\title{
Extensive Defects of Mitochondrial Electron-Transfer Chain in Muscular Cytochrome $c$ Oxidase Deficiency
}

\author{
MASASHI TANAKA, SHIGEAKI MIYABAYASHI, MORIMITSU NISHIKIMI, HIROSHI SUZUKI, \\ YOSHIHARU SHIMOMURA, KEN ITO, KUNIAKI NARISAWA, KEIYA TADA, AND \\ TAKAYUKI OZAWA
}

Department of Biomedical Chemistry, Faculty of Medicine, University of Nagoya, 65 Tsuruma-cho, Showa-ku, Nagoya 466, Japan [M.T., M.N., H.S., Y.S., T.O.]; and Department of Pediatrics, Tohoku University School of Medicine, 1-1 Seiryo-machi, Sendai 980, Japan [S.M., K.I., K.N., K.T.]

\begin{abstract}
This study was undertaken to estimate the extent of molecular defects in the mitochondrial electrontransfer chain of a patient with mitochondrial myopathy. Biochemical and immunochemical studies were performed on the skeletal muscle mitochondria. Spectrophotometry and enzyme activity measurements localized a definite defect at the segment of cytochrome $c$ oxidase (complex IV) of the electron-transfer chain. Immunoblotting and immunoprecipitation studies using the anti-complex IV antibody revealed that the contents of subunits $1,4,5,6$, and 7 of complex IV were markedly diminished and that subunit 2 was almost absent. Immunohistochemistry of the muscle tissue revealed a considerable accumulation of immunoreactive materials of complex IV in the ragged-red fibers. The immunoblots using the anti-NADH-ubiquinone oxidoreductase antibody demonstrated that the contents of NADH-ubiquinone oxidoreductase subunits were $47 \%$ of control and that the contents of three subunits were considerably decreased. The contents of ubiquinol-cytochrome $c$ oxidoreductase subunits were also somewhat low $(77 \%$ of control) and one of the minor contaminants detected in the control was completely absent. High-resolution onedimensional sodium dodecyl sulfate-urea-gel electrophoresis disclosed that six additional unidentified polypeptides in the control were markedly diminished or completely missing. These results demonstrate that the molecular defects in the mitochondrial electron-transfer chain are more extensive than would be expected from either spectral analysis or enzyme activity measurements alone, and involve not only complex IV but also NADH-ubiquinone oxidoreductase and ubiquinol-cytochrome $c$ oxidoreductase and several unidentified mitochondrial proteins. (Pediatr Res 24: 447-454, 1988)
\end{abstract}

\section{Abbreviations}

Complex I, NADH-ubiquinone oxidoreductase Complex II, succinate-ubiquinone oxidoreductase Complex III, ubiquinol-cytochrome $c$ oxidoreductase Complex IV, cytochrome $c$ oxidase

Received October 15, 1987; Accepted June 1, 1988.

Correspondence Prof. Takayuki Ozawa, Department of Biomedical Chemistry, Faculty of Medicine, University of Nagoya, 65 Tsuruma-cho, Showa-ku, Nagoya 466, Japan.

Supported by the Grants-in-Aid for General Scientific Research (62570128) to M.T. and for Scientific Research on Priority Areas (62617002) to T.O. from the Ministry of Education, Science and Culture, Japan and by Grant 86-02-39 from National Center for Nervous, Mental and Muscular Disorders of the Ministry of Health and Welfare, Japan to T.O.
Complex V, $F_{0} F_{1}$-ATPase

SDS, sodium dodecyl sulfate

PAGE, polyacrylamide gel electrophoresis

PBS, phosphate-buffered saline

MELAS, mitochondrial myopathy, encephalopathy, lactic acidosis, and stroke-like episodes

Mitochondrial myopathies are miscellaneous entities characterized by muscular atrophy and morphologically abnormal mitochondria (1). Deficiencies in the oxidative phosphorylation system have been recognized as one of the causes of mitochondrial myopathies, and complex IV deficiency is the most frequent disorder (2).

Complex IV deficiency has been classified into the following four forms on the basis of clinical characteristics: 1 ) fatal infantile form with or without renal dysfunction or cardiomyopathy (3, $4)$; 2) benign infantile form, spontaneously remitting myopathy of infancy (5); and 3) encephalomyopathic form (6), including Leigh's necrotizing encephalomyelopathy (7). In addition, focal deficiency of complex IV, mainly observed in Kearns-Sayre syndrome (8) or in chronic progressive external ophthalmoplegia (CPEO) (9), is also recognized. However, the molecular basis for the heterogeneity in the clinical features of complex IV deficiency is not fully elucidated.

The electron-transfer chain is divided into four segments: complexes I, II, III, and IV. These complexes, together with complex V, are involved in the oxidative phosphorylation. They are multisubunit enzymes; there are 25 subunits in complex I, 4-5 in complex II, 9-10 in complex III, 7-8 in complex IV, and 12-14 in complex V (10). In some cases of complex IV deficiency (11-14), it has been reported that not only complex IV but also other segments of the respiratory chain are affected. But the molecular mechanism of combined deficiency of respiratory complexes is not fully elucidated.

Although spectral and enzymologic analyses have been used to study the defects in the oxidative phosphorylation system, they provide only limited information on the structure and function of the electron-transfer complexes. Therefore, an improved analysis of the subunits of defective complexes is essential for gaining insight into the fundamental abnormality. Moreover, the presence of a combined deficiency requires that the analysis of subunits should cover the whole system of the electron-transfer chain. For this purpose, methods for systematically analyzing mitochondrial proteins from a small amount of biopsied tissue have been established for use in this study. 
These methods were used to ascertain if molecular abnormality is confined to subunits of complex IV or extended to subunits of other complexes. This question is of central importance in deciding if the deficiency of multiple complexes is an epiphenomenon of the complex IV deficiency or if the cause of the defects are common among the complexes. In the present study of skeletal muscle mitochondria from a patient with mitochondrial myopathy, the results indicate that even in a typical case of complex IV deficiency the molecular defect was more extensive than would be expected from either the spectral or enzymologic analyses.

\section{CASE REPORT}

A 6-yr-old Japanese boy of a normal gestation and birth was completely asymptomatic and fully active until age 3 when decreased exercise tolerance was noted. An older brother was normal and there was no consanguinity. At age 6 , he was presented to the Tohoku University Hospital because of retarded growth. Generalized muscular atrophy and weakness were evident. Physical examination of the heart, eyes, and CNS was normal. There was slight mental retardation (IQ 77 by the Tanaka-Binet method). CT and MRI showed no abnormality. Urinalysis indicated neither glucosuria nor aminoaciduria with negative findings upon loading with $\mathrm{NH}_{4} \mathrm{Cl}$. Laboratory investigations revealed lactic acidosis with a marked increase in venous lactate level during an exercise tolerance test. A glucose loading test showed no elevation in the lactate level. Loading of ketogenic diet increased the levels of venous lactate and ketone bodies with appearance of dicarboxylic acids in the urine. Intravenous injection of methylene blue resulted in a significant decrease in venous lactate level. Enzymologic examination of cultured skin fibroblasts demonstrated normal activities of mitochondrial electrontransfer enzymes as well as of the pyruvate dehydrogenase complex, pyruvate carboxylase, and phosphoenolpyruvate carboxykinase. Cytochrome $c$ oxidase activity was normal in biopsied liver, cultured fibroblasts, and leukocytes (data not shown), but was markedly diminished in biopsied muscle (see "Results"), indicating that the defect is localized in the skeletal muscle. Electron microscopy revealed a marked increase in number of mitochondria in the skeletal muscle fibers.

\section{METHODS}

Preparation of mitochondria. Skeletal muscle was taken from the vastus lateralis by open biopsy under general anesthesia after signed permission and informed concent were given. Mitochondria were isolated from human control and patient skeletal muscles (approximately $0.7 \mathrm{~g}$ ) essentially according to the method of Kennaway et al., (15).

Measurement of enzymic activity. Activity of complex I-III, complex II-III, and succinate dehydrogenase (a part of complex II) were determined according to the methods of Sanadi et al. (16), Kennaway et al. (15), and Pennington (17), respectively. Complex IV activity was measured by the rate of cyanidesensitive oxidation of reduced cytochrome $c$ essentially as described by Wharton and Tzagoloff $(18) . \mathrm{Mg}^{2+}$-dependent ATPase (complex V) activity was measured by the method of Kagawa (19).

Determination of cytochromes. Reduced minus oxidized spectra of cytochromes were recorded at room temperature in a Hitachi 557 double-wavelength double-beam spectrophotometer using a reference wavelength of $570 \mathrm{~nm}$. Cytochromes were reduced by addition of $10 \mathrm{mM}$ succinate and $1 \mathrm{mM} \mathrm{KCN}$ or by addition of a few grains of sodium dithionite. The concentrations of cytochromes were calculated using the extinction coefficients reported by Bookelman et al. (20). Protein in the mitochondrial preparation was measured by the method of Lowry et al. (21).

Purification of enzyme complexes. All mitochondrial enzyme complexes used in this study were purified from beef heart mitochondria isolated according to the method of Crane et al. (22). Complex I was isolated by the method of Hatefi (23). Soluble NADH dehydrogenase and iron-protein fragments were prepared from complex I as described by Galante and Hatefi (24). Complex III was isolated as described by Rieske et al. (25) and was further purified by phenyl-Sepharose chromatography and cytochrome $c$-Sepharose chromatography by the method of Ozawa et al. (26). Complex IV was isolated by the method of Fowler et al. (27), as modified by Tzagoloff and MacLennan (28) or by Capaldi and Hayashi (29), and was further purified by a combination of hydrophobic interaction chromatography on phenyl-Sepharose and affinity chromatography on cytochrome $c$-Sepharose according to the method of Tanaka and Ozawa (30). The $F_{1}$ part of complex $V$ was isolated by the method of Vogel (31). Most of the detergent present in the highly purified preparations of the complexes was removed before immunization by mixing with Bio-Beads SM-2 (Bio-Rad Laboratories, Richmond, CA).

Preparation of antibodies. Antibodies against mitochondrial enzymes were raised in rabbits by intradermal injections of $1 \mathrm{mg}$ of protein for complexes I, III, and IV, and $0.5 \mathrm{mg}$ of protein for $\mathrm{F}_{1}$-part of complex $\mathrm{V}$; the proteins were emulsified in $1 \mathrm{ml}$ of $0.9 \% \mathrm{NaCl}$ with $1 \mathrm{ml}$ of Freund's complete adjuvant. Booster injections of the same mixture were administered 3, 5, and $7 \mathrm{wk}$ later. One week after the last injection, blood was withdrawn from the carotid artery.

Immunohistochemistry for complex IV. For immunohistochemical studies, skeletal muscle biopsy specimens were frozen in liquid nitrogen-cooled isopentane and cross-sectioned to 10$\mu \mathrm{m}$ thickness in a cryostat. Sections were incubated for $5 \mathrm{~min}$ at room temperature with $0.1 \%$ Triton $\mathrm{X}-100$, and washed twice with cold PBS. They were treated for 20 min with $0.03 \% \mathrm{H}_{2} \mathrm{O}_{2}$ in methanol to block endogenous peroxidase activity. After being washed twice with cold PBS, the sections were overlayed with $10 \%$ normal goat serum for $20 \mathrm{~min}$ in a humidified chamber. Then they were covered with the anti-complex IV antibody (1:100 dilution) for $30 \mathrm{~min}$ at $37^{\circ} \mathrm{C}$. The immunohistochemical stain was performed by the avidin-biotin complex method essentially according to Sato et al. (32).

Electrophoresis of proteins. SDS-PAGE was carried out essentially according to Kadenbach et al. (33) using electrophoresis apparatuses from Marysol Industry Co., Ltd., Tokyo, Japan: type KS-8000SE for standard-sized slab gels $(13.5 \times 12 \times 0.1 \mathrm{~cm})$ and type KS-8430S for large-sized slab gels $(16 \times 35 \times 0.1 \mathrm{~cm})$. An exponential acrylamide-gradient from 9.38 to $18.75 \%$ and a glycerol-gradient from 0 to $20 \%$ were formed using a two-channel pump as described by Douglas et al. (34). Protein samples were solubilized in a sample buffer containing $8 \mathrm{M}$ urea, $10 \%$ glycerol, $5 \%$ 2-mercaptoethanol, $62.5 \mathrm{mM}$ Tris- $\mathrm{HCl}, \mathrm{pH} 6.8,2 \% \mathrm{SDS}$, and $0.001 \%$ bromophenol blue, and were incubated at $37^{\circ} \mathrm{C}$ for $30 \mathrm{~min}$. Gels were stained either with Coomassie brilliant blue R-250 or by the silver staining method of Merril et al. (35). A mixture of cross-linked cytochrome $c$ (Oriental Yeast Co., Ltd., Tokyo, Japan) was used as the molecular weight marker.

Electroblotting and immunochemical detection of mitochondrial proteins. Mitochondrial proteins separated by SDS-PAGE were electrophoretically transferred to a Durapore GVHP filter (Millipore Co., Bedford, MA) according to the method of Towbin et al. (36) using an electroblotting apparatus (type KS-8450IIGMT, Marysol). An electric current of $200 \mathrm{~mA}$ was applied for $1 \mathrm{~h}$ in a cold room $\left(4^{\circ} \mathrm{C}\right)$. The electrode buffer contained 25 $\mathrm{mM}$ Tris, $192 \mathrm{mM}$ glycine, $20 \%$ (vol/vol) methanol, and $0.1 \%$ SDS. The electrophoretic blots were soaked in $3 \%$ gelatin in saline $(0.5 \mathrm{M} \mathrm{NaCl}$ and $20 \mathrm{mM}$ Tris- $\mathrm{HCl}, \mathrm{pH} 7.4)$ for $1 \mathrm{~h}$ at room temperature to saturate additional protein binding sites. They were then incubated with antisera diluted 1:100 into $1 \%$ gelatin in saline for $2 \mathrm{~h}$ at room temperature. After a brief soaking in water and washing twice for $10 \mathrm{~min}$ with saline, the filters were incubated for $45 \mathrm{~min}$ at room temperature with the second antibody, goat anti-rabbit IgG (Medical and Biological 
Laboratories, Tokyo, Japan) diluted 1:500 into 1\% gelatin in saline. They were again washed as above and then incubated with the third antibody, rabbit peroxidase-antiperoxidase complex (Cappel Laboratories, Cochranville, PA) diluted 1:1000 into $1 \%$ gelatin in saline. After washing twice with saline, the blots were then soaked in a color developing solution containing 0.015\% 4-chloro-1-naphthol (Bio-Rad Laboratories, Richmond, CA), $0.015 \% \mathrm{H}_{2} \mathrm{O}_{2}$, and $16.7 \%$ (vol/vol) methanol in saline. The reaction was allowed to proceed for 5-10 min with shaking and was stopped by washing with water. For the densitometry of the visualized bands, the stained filters were scanned with a Shimadzu CS-930 chromatoscanner (Shimadzu Corporation, Kyoto, Japan).
Immunoprecipitation of complex $I V$. Mitochondrial proteins $(25-250 \mu \mathrm{g})$ were solubilized with $0.4 \mathrm{ml}$ of $5 \%$ Triton X-100 in $0.2 \mathrm{M}$ sodium phosphate buffer, $\mathrm{pH}$ 7.2. Insoluble materials were removed by centrifugation at $10,000 \times g$ for $10 \mathrm{~min}$. After incubation with $8 \mu \mathrm{l}$ of anti-complex IV serum at $4^{\circ} \mathrm{C}$ overnight, the antigen-antibody complex formed was bound to $15 \mu \mathrm{l}$ of protein A-Sepharose CL-4B (Pharmacia, Uppsala, Sweden). After washing four times with $0.8 \mathrm{ml}$ of $1 \%$ Triton $\mathrm{X}-100$ in the same buffer by centrifugation at $10,000 \times g$ for $5 \mathrm{~min}$ and resuspension, the immune complex was released from the gel beads by incubation with $20 \mu \mathrm{l}$ of sample buffer containing $8 \mathrm{M}$ urea, $10 \%$ glycerol, $2 \% \mathrm{SDS}, 5 \%$ (vol/vol) 2-mercaptoethanol, and $62.5 \mathrm{mM}$ Tris- $\mathrm{HCl}, \mathrm{pH} 6.8$, at $37^{\circ} \mathrm{C}$ for $30 \mathrm{~min}$.
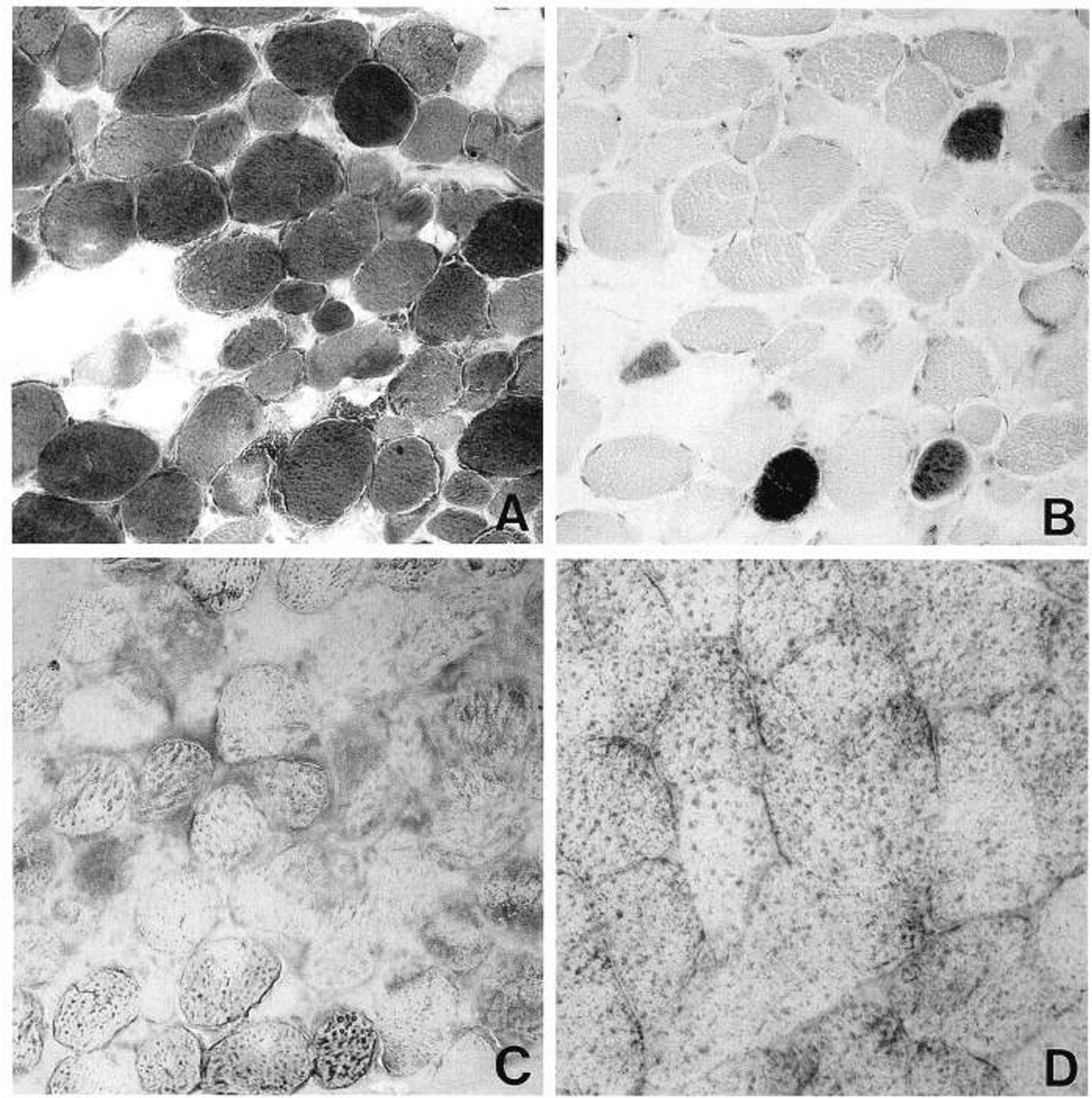

Fig. 1. Histochemistry and immunohistochemistry of the skeletal muscle from patient. $A$, Gomori's modified trichrome stain. $B$, activity staining for complex IV. $C$, immunostaining for complex IV. $D$, immunostaining of normal skeletal muscle. 


\section{RESULTS}

Histochemistry and immunochemistry of the skeletal muscle of the patient are shown in Figure 1. Abundant ragged-red fibers can be observed, indicating proliferation of mitochondria in the fiber (Fig. 1A). The histochemistry for complex IV activity demonstrated decreased staining in most of the fibers including ragged-red fibers (Fig. $1 B$ ). Despite the decreased stain for activity, the ragged-red fibers were heavily immunostained when using the anti-complex IV antibody (Fig. 1C). In contrast, the nonragged-red fibers were less intensely immunostained than the ragged-red fibers or the fibers in the control muscle (Fig. 1D). These results indicate that the immunologically detectable subunits of complex IV accumulated in the ragged-red fibers in which defective mitochondria were proliferated.

The activities of enzymes involved in energy transduction in the patient mitochondria are shown in Table 1 . Complex I-III and complex II-III activities were moderately diminished, being 40 and $66 \%$ of mean control values, respectively. Succinate dehydrogenase (a part of complex II) activity was close to normal levels, but cytochrome $c$ oxidase activity was greatly diminished and was less than $5 \%$ of the control value. When the homogenates from control and patient tissues were mixed, there was no reduction of activity over the expected value from complex IV activity of each tissue, indicating that the reduced activity in the patient muscle was not due to the presence of an inhibitor. When complex IV activity was measured after incubation of the homogenate of the patient tissue at various temperatures, the decrease in activity was comparable to that observed in the control; there was no thermoinstability of complex IV in the patient mitochondria. $\mathrm{Mg}^{2+}$-dependent ATPase (complex V) activity was within the normal range. These results localize a major defect at the complex IV segment and minor defects at the segments of complexes I and III of the mitochondrial respiratory chain.

The spectrum of reduced minus oxidized cytochromes showed complete lack of the peak of cytochrome $a a_{3}$ that is normally seen at $605 \mathrm{~nm}$ (Fig. 2). Cytochrome $a a_{3}$ could not be detected even when dithionite was used as a reductant. Calculation of cytochrome contents (Table 2) confirmed the fact that there is a major lesion in complex IV and a minor lesion in complex III inasmuch as the cytochrome $a a_{3}$ content was less than $4 \%$ of the control value and the contents of cytochromes $b$ and $c+c_{1}$ were both $57 \%$ of the control values.

Complex IV consists of at least seven subunits $(10,30)$. To determine which of these subunits were affected in the patient, immunoblot analysis was performed. In Figure 3, the polypeptide profile of the patient mitochondria before the electroblotting (lane 4 ) is compared with those of the normal human mitochondria (lane 3 ) and beef heart mitochondria (lane 2) with reference to the purified preparation of beef heart complex IV (lane 1). Although the profiles are, as a whole, essentially similar among the three mitochondrial preparations, it is noted that the density

Table 1. Activity of mitochondrial enzymes in skeletal muscle mitochondria

\begin{tabular}{lcr}
\hline & \multicolumn{2}{c}{$\begin{array}{c}\text { Activity } \\
\text { (nmol/min/mg of protein) }\end{array}$} \\
\cline { 2 - 3 } \multicolumn{1}{c}{ Enzyme } & $\begin{array}{c}\text { Control } \\
\text { mean } \pm \text { SD }(n)\end{array}$ & Patient (\%) \\
\hline $\begin{array}{l}\text { Rotenone-sensitive NADH-cyto- } \\
\text { chrome } c \text { reductase } \\
\quad \text { complex I-III) }\end{array}$ & $106 \pm 60(5)$ & $42(40)$ \\
$\begin{array}{l}\text { Succinate-cytochrome } c \text { reductase } \\
\quad \text { complex II-III) }\end{array}$ & $174 \pm 24(5)$ & $114(66)$ \\
$\begin{array}{l}\text { Succinate dehydrogenase } \\
\text { Cytochrome } c \text { oxidase } \\
\mathrm{Mg}^{2+} \text {-dependent ATPase }\end{array}$ & $118 \pm 23(5)$ & $98(83)$ \\
\hline
\end{tabular}

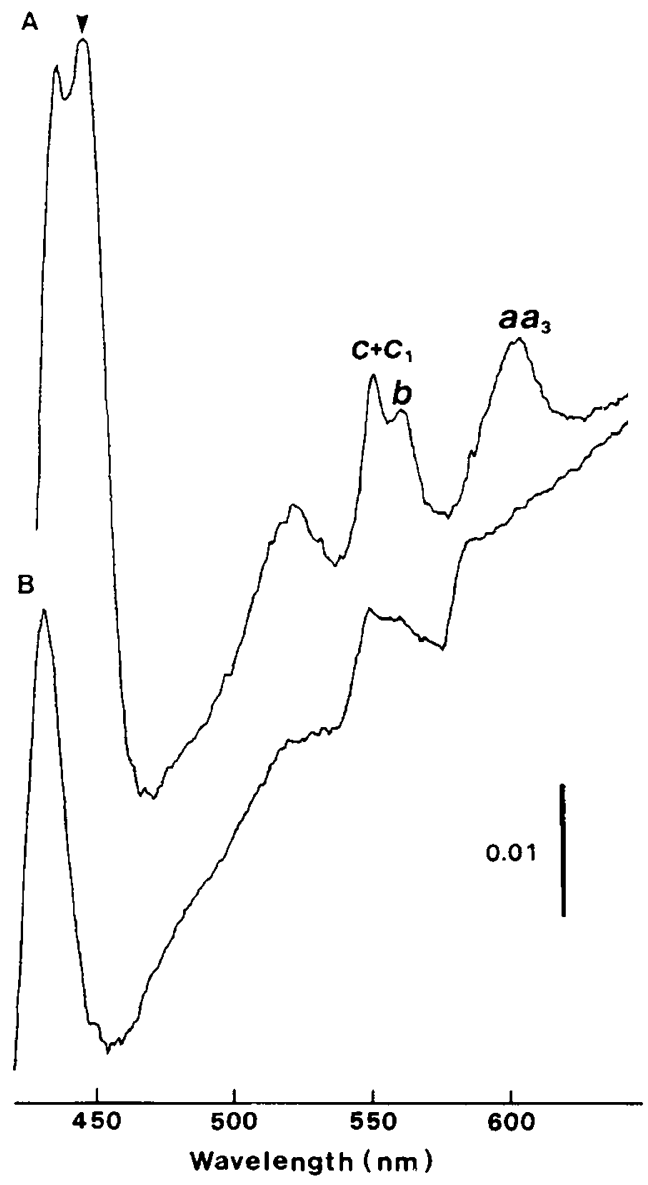

Fig. 2. Succinate-reduced minus oxidized spectra of cytochromes in control human skeletal muscle mitochondria $(A)$ and in patient skeletal muscle mitochondria $(B)$. The arrowhead indicates the absorption peak of cytochrome $a a_{3}$ in the $\gamma$-region. Protein concentration was $1 \mathrm{mg} / \mathrm{ml}$. Scale of absorbance is indicated by the bar.

Table 2. Contents of cytochromes in skeletal muscle mitochondria

\begin{tabular}{ccc}
\hline & \multicolumn{2}{c}{$\begin{array}{c}\text { Contents* } \\
\text { (nmol/mg of protein) }\end{array}$} \\
\cline { 2 - 3 } Cytochromes & Control & Patient $(\%)$ \\
\hline$a+a_{3}$ & 0.48 & $<0.02(<4)$ \\
$b$ & 0.54 & $0.31(57)$ \\
$c+c_{1}$ & 0.63 & $0.36(57)$ \\
\hline
\end{tabular}

* Contents are calculated from the data in Figure 2.

of several polypeptide bands are diminished in the patient mitochondria (see Fig. 6 for more detailed analysis). Lane 5 in Figure 3 shows antibody binding to purified complex IV of beef heart. Cytoplasmically synthesized subunits, 4-7, were easily detected in purified complex IV. However, among the mitochondrially synthesized subunits, subunits 1 and 3 did not react with the antiserum used and subunit 2 was only slightly discernible. A similar pattern was seen with beef heart mitochondria (Fig. 3, lane 6) and normal human skeletal muscle mitochondria (Fig. 3 , lane 7) but the intensity of subunit 6 was low in human mitochondria as compared to beef mitochondria. In the patient mitochondria (Fig. 3, lane 8), the protein bands corresponding to subunits 4,5 , and 7 were barely discernible. Densitometry showed that the amounts of subunits 4,5 , and 7 were 13,5 , and $2 \%$ of control values, respectively. This finding is in agreement with the reduced activity of complex IV in the patient mitochondria. The electrophoretic mobilities of the immunochemically 


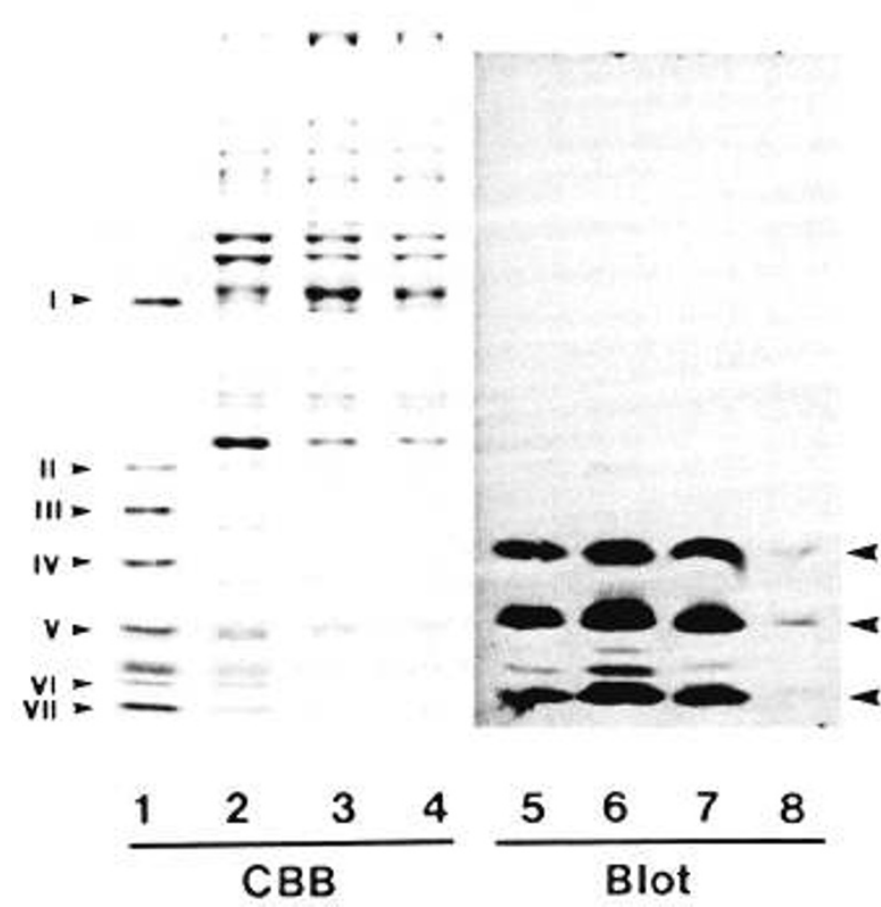

Fig. 3. SDS-PAGE of mitochondrial proteins and immunochemical detection of complex IV subunits. Lanes 1-4 (CBB), an SDS-gel was stained for protein with Coomassie brilliant blue R-250. Lane $1,10 \mu \mathrm{g}$ of complex IV; lane 2, $25 \mu \mathrm{g}$ of beef heart mitochondria; lane 3,25 $\mu \mathrm{g}$ of control human skeletal muscle mitochondria; lane 4, $25 \mu \mathrm{g}$ of patient skeletal muscle mitochondria. Lanes 5-8 (blot), mitochondrial proteins on a gel were electrophoretically transferred to Durapore filter and complex IV subunits were detected immunochemically. Lane $5,1 \mu \mathrm{g}$ of complex IV; lane $6,25 \mu \mathrm{g}$ of beef heart mitochondria; lane $7,75 \mu \mathrm{g}$ of control human skeletal muscle mitochondria; lane $8,75 \mu \mathrm{g}$ of patient skeletal muscle mitochondria. The roman numbers represent the subunit numbers of complex IV. The arrowheads on the right indicate the subunits, whose density is markedly decreased.

detected subunits in the patient were the same as those of the subunits in the control.

Inasmuch as the mitochondrially synthesized subunits of complex IV could not be visualized by the immunoblotting method, immunoprecipitation of the enzyme was carried out with detergent-solubilized mitochondria (Fig. 4). Antiserum specific to subunits 4-7 coprecipitated subunits 1,2 , and 3 , although the band of subunit 3 was very faint in the immunoprecipitate, probably because this subunit is easily dissociated from the enzyme by treatment with detergent (37). Compared with the beef enzyme, either purified (lane 1) or immunoprecipitated from beef heart mitochondria (lane 2), the human enzyme from skeletal muscle mitochondria (lane 3 ) had a similar polypeptide composition, but the electrophoretic mobility of human subunit 2 was distinctly higher than that of beef subunit $2(38)$. In the patient mitochondria (lane 4), none of the subunits could be detected except for subunit 5 which was barely discernible when the same amount of mitochondrial protein was used as in the control. When the amount of mitochondrial protein to be analyzed were increased, the abnormality in subunit composition of the enzyme in the defective mitochondria could be demonstrated (lane 5). Subunits 1 and 4-7 could be detected in the immunoprecipitate from the patient mitochondria, but no protein band was seen at the position of subunit 2 (arrowhead in lane 5).

To investigate possible abnormality in other components of the mitochondrial oxidative phosphorylation system, immunoblotting experiments were performed using antibodies raised against complexes I and III, and the $F_{1}$-part of complex V. The immunoblotting using antiserum against complex I (Fig. 5A)

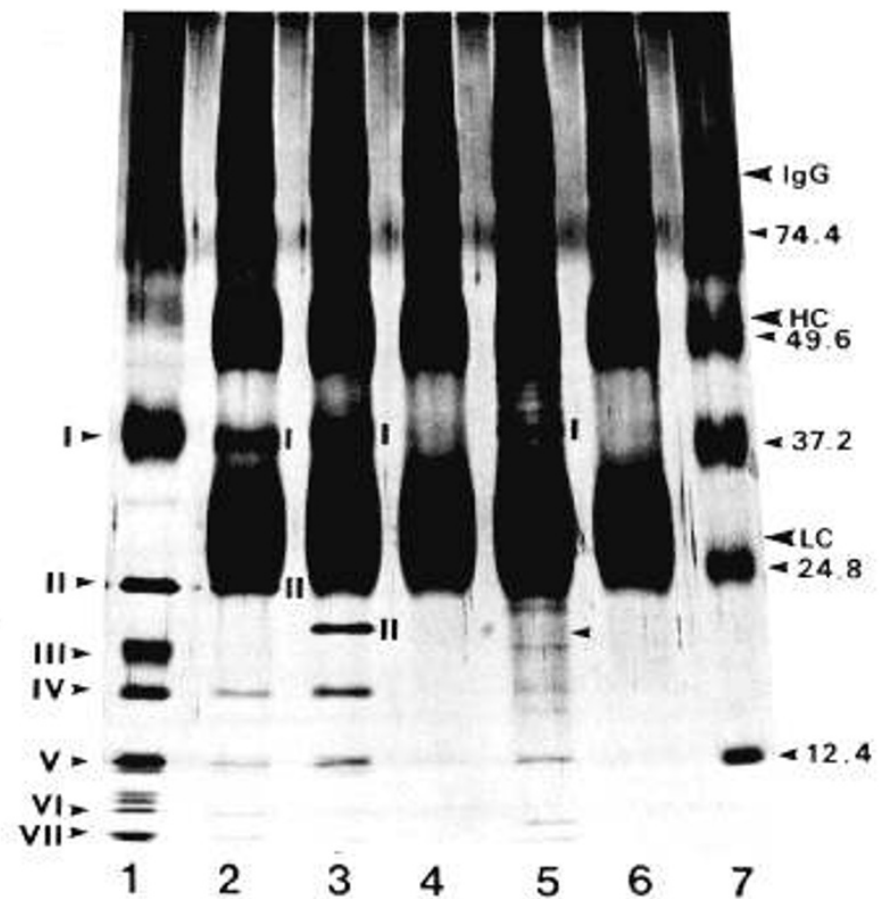

Fig. 4. Detection of complex IV subunits by immunoprecipitation using protein A-Sepharose CL-4B. Lane 1, $1 \mu \mathrm{g}$ of complex IV; lane 2, $25 \mu \mathrm{g}$ of beef heart mitochondria; lane $3,75 \mu \mathrm{g}$ of control human skeletal muscle mitochondria; lane 4, 75 $\mu \mathrm{g}$ of patient skeletal muscle mitochondria; lane $5,250 \mu \mathrm{g}$ of patient mitochondria; lane 6, blank, antiserum only without mitochondrial proteins; lane $7,0.1 \mu \mathrm{g}$ each of molecular weight marker proteins, whose mol. wt. are indicated in $\mathrm{kDa}$ on the right side. The electrophoretic positions of immunoglobulin $(I g G)$, heavy chain $(H C)$, and light chain $(L C)$ are also indicated. Note the difference in electrophoretic mobility of subunit 2 of complex IV between beef heart mitochondria and human skeletal muscle mitochondria (lanes 2 and 3 ). Subunit 2 is not detected in patient mitochondria (lane 5 , arrowhead).

detected at least 20 subunits both in purified complex I (lane 1) and in beef heart mitochondria (lane 2), and 18 subunits in normal human skeletal muscle mitochondria (lane 3) and in patient skeletal muscle mitochondria (lane 4). The content of three subunits in the patient (arrowheads in Fig. 5A, lane 4) were considerably diminished. The content of complex I subunits in the patient mitochondria was $48 \%$ of that in the control, as calculated from the total peak area of densitometric traces of the blots. This is in rough agreement with the data from activity measurements (Table 1).

The immunoperoxidase-stained transblots using anti-complex III serum (Fig. $5 B$ ) show that antibodies against core proteins 1 and 2 (bands 1 and 2 in lane 1 ), cytochrome $c_{1}$ (band 4), Rieske iron-sulfur protein (band 5), and ubiquinone-binding protein (band 6) react with corresponding components of normal human mitochondria (Fig. $5 B$, lane 3 ) and of the defective mitochondria (Fig. 5B, lane 4). The content of complex III subunits in the patient mitochondria was $77 \%$ of that in the control, as calculated by densitometry. The decreased content of complex III subunits is correlated with the decrease in spectroscopically measurable content of cytochrome $b$ and $c+c_{1}$ and with the diminished activities of rotenone-sensitive NADH-cytochrome $c$ reductase and succinate-cytochrome $c$ reductase. In addition to the five subunits of complex III described above, four minor bands of contaminating polypeptides were detected in a preparation of purified complex III (Fig. $5 B$, lane 1 ), in beef heart mitochondria (lane 2), and in control human skeletal muscle mitochondria, indicating that these four minor components are constituents of the normal mitochondria and are present in small 
A Complex 1

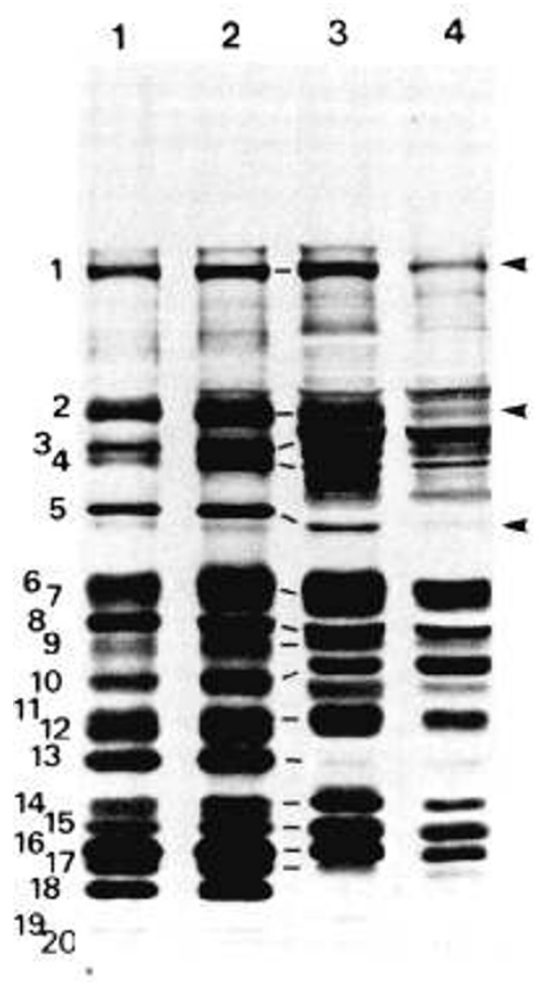

B Complex III

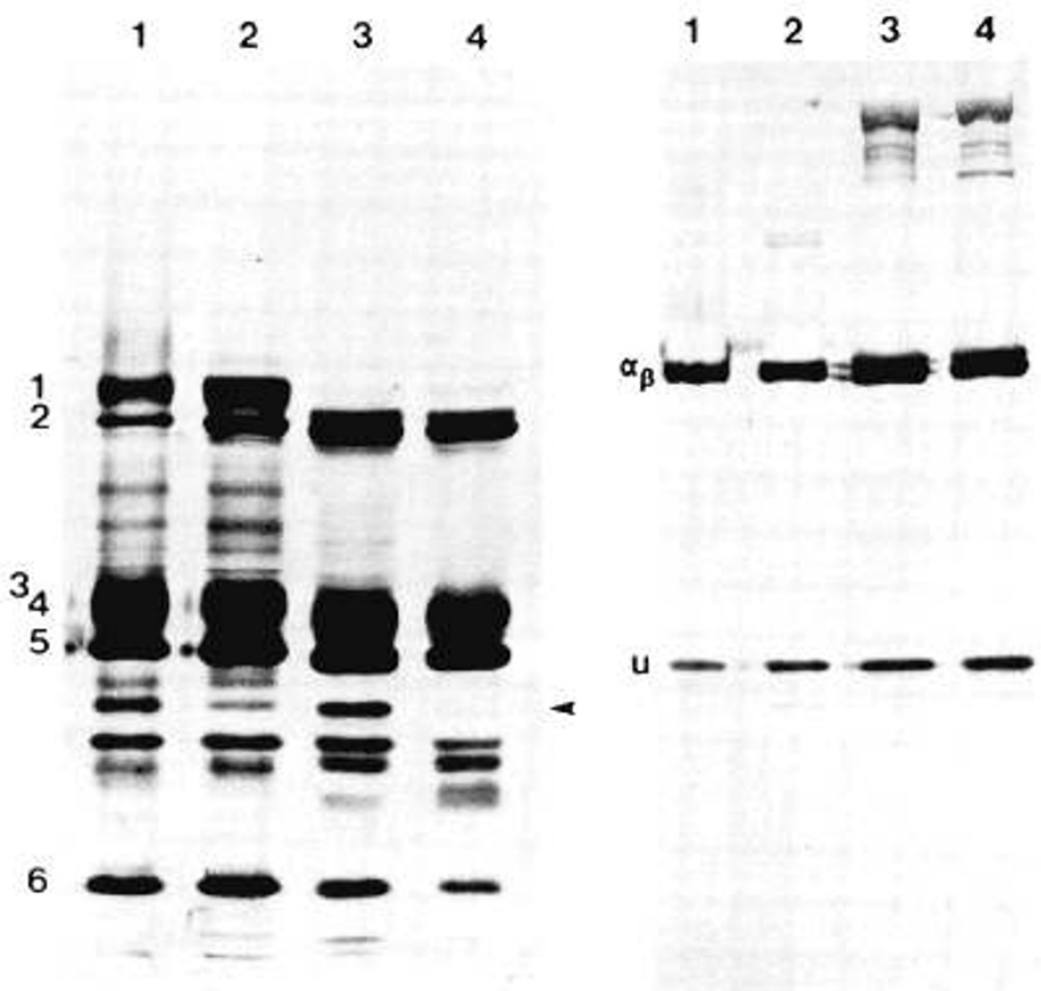

Fig. 5. Immunochemical detection of subunits of complexes I, III, and V after SDS-PAGE. A, subunits of complex I. Lane 1,2 $\mu \mathrm{g}$ of complex I; lane 2, $25 \mu \mathrm{g}$ of beef heart mitochondrial protein; lane 3,75 $\mu \mathrm{g}$ of control human mitochondrial protein; lane 4, 75 $\mu \mathrm{g}$ of patient mitochondrial protein. Subunits were numbered tentatively. Three subunits that are markedly decreased in contents in patient mitochondria are indicated by arrowheads. $B$, subunits of complex III. Lane $1,1 \mu \mathrm{g}$ of complex III. Lanes $2-4$, same as in $A$. The subunits of complex III are numbered on the left side: $I$ and 2, core proteins; 3, cytochrome $b ; 4$, cytochrome $c_{1} ; 5$, Rieske iron-sulfur protein; and 6 , ubiquinone-binding protein. One of four minor components that has a mol. wt. of approximately 20,000 is missing in the patient mitochondria (arrowhead). C, subunits of complex V. Lane $1,1 \mu \mathrm{g}$ of $\mathrm{F}_{1}$-part of complex V. Lanes 2-4, same as in $A$. Subunits $\alpha$ and $\beta$ of complex V and an unidentified component $(u)$ are detected.

amounts even in a highly purified complex III preparation. It is noted that one of these polypeptides is absent in the patient mitochondria (arrowhead in Fig. 5B, lane 4). The electrophoretic mobility of this polypeptide did not coincide with that of subunits of complex IV or complex I.

The immunoblots with antibody against the $F_{1}$-part of complex V (Fig. $5 C$ ) visualized two subunits, $\alpha$ and $\beta$, of complex $\mathrm{V}$ and an unidentified polypeptide $(u)$ in purified enzyme (lane 1 ), and in beef heart mitochondria (lane 2). A similar pattern was observed with normal human skeletal muscle mitochondria (lane 3 ) and patient skeletal muscle mitochondria (lane 4). There was no difference in the immunostain density of subunits $\alpha$ and $\beta$ and the unidentified subunit between the control and the patient. Subunits $\alpha$ and $\beta$ of complex $\mathrm{V}$ serve as an internal standard that certifies that the subunits of complexes IV are specifically deficient and that the subunits of complexes I and III are also moderately diminished in the patient mitochondria.

Figure 6 shows the polypeptide patterns of mitochondrial proteins on large-sized slab gels visualized by silver staining. They demonstrate higher resolution than those on the standardsized slab gels stained with Coomassie brilliant blue (Fig. 3, lanes 1-4). The immunoblotting and immunoprecipitation experiments described above revealed that the electrophoretic mobilities of subunits in the complexes of the mitochondrial oxidative phosphorylation system are similar between beef and human. Therefore, this method allows direct identification of polypeptide bands of human skeletal muscle mitochondria (Fig. 6, lanes 2 and 3 ) by comparison of their electrophoretic mobilities with those of the subunits in the complexes purified from beef heart mitochondria (Fig. 6, lanes 4-9). At least 11 polypeptide bands are shown to be markedly diminished in density in the patient mitochondria (Fig. 6, lane 1, arrowheads) as compared to each band of the control. Among them, five bands are identified as subunits 2-4 of complex IV. Six other polypeptide bands cannot be identified on the basis of electrophoretic mobility. One protein band, indicated by $U$ in Figure 5 , lane 1 , probably corresponds to the deficient minor component demonstrated by immunoblotting using anti-complex III serum (Fig. 5B, lane 4, arrowhead). Thus, this approach also makes it possible to detect abnormality in polypeptides that are not constituents of the complexes and therefore are not specifically detected by immunologic methods.

\section{DISCUSSION}

The results of the present study demonstrate that the decreased complex IV activity (Table 1) and the absence of cytochrome $a a_{3}$ (Fig. 2, Table 2) are based on marked deficiency of complex IV subunits (Fig. 3). Normal thermostability of enzymic activity in the homogenate of the patient muscle implies that the decreased amount of subunits is possively due to a limited synthesis of any of the subunits rather than accelerated degradation of the complex. The observation that subunit 2 was most markedly diminished among complex IV subunits (Fig. 4) suggests that the defect in subunit 2 impairs proper assembly of the complex, resulting in a secondary deficiency of other complex IV subunits and prosthetic groups. However, we cannot exclude the possibility that the decreased content of subunit 2 is secondary to a defect in one of the nuclearly encoded subunits. It is generally accepted that subunit 1 contains binding sites for two heme 


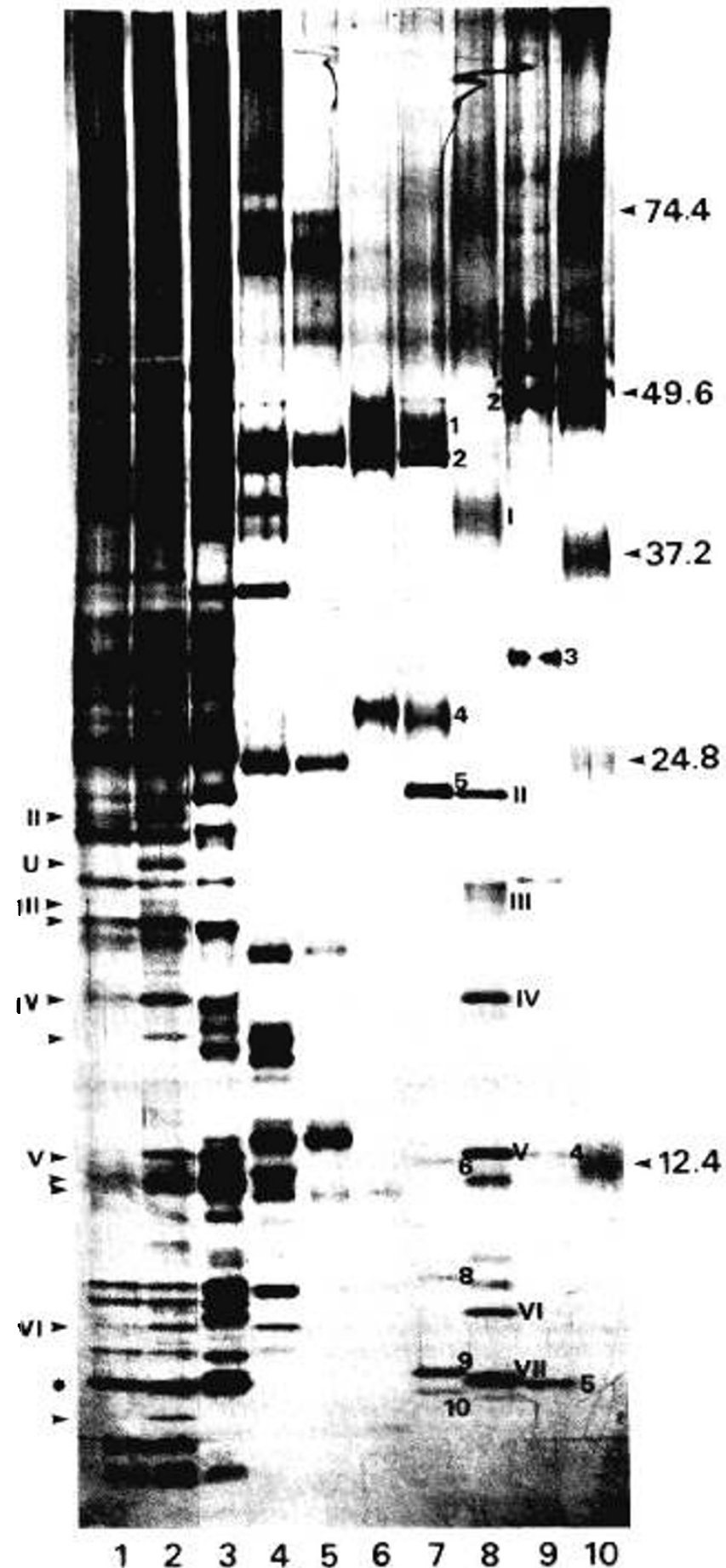

Fig. 6. Survey for deficient polypeptides in mitochondria isolated from patient skeletal muscle by high-resolution one-dimensional SDSPAGE. Lane $1,15 \mu \mathrm{g}$ of patient skeletal muscle mitochondria; lane 2, $15 \mu \mathrm{g}$ of control human skeletal muscle mitochondria; lane $3,15 \mu \mathrm{g}$ of beef heart mitochondria; lane 3, $4 \mu \mathrm{g}$ of complex I; lane 5, $2 \mu \mathrm{g}$ of the iron-protein fragment of complex I; lane 6,2 $\mu \mathrm{g}$ of the flavoprotein fragment of complex I; lane 7,2 $\mu \mathrm{g}$ of complex III; lane $8,2 \mu \mathrm{g}$ of complex IV; lane 9, $2 \mu \mathrm{g}$ of the $\mathrm{F}_{1}$-part of complex V; lane 10, $0.1 \mu \mathrm{g}$ each of the mol. wt. marker proteins. Polypeptide bands whose density is markedly decreased in the patient as compared to the control are indicated by arrowheads. The roman numbers represent subunit numbers of complex IV. The unidentified polypeptide $(U)$ corresponds to the minor component detected by immunoblotting using the anti-complex III antibody (Fig. 5B, arrowhead). Numbers in lanes 7,8 , and 9 represent the subunit numbers of complexes III, IV, and V, respectively. The mol. wt. of marker proteins are indicated in $\mathrm{kDa}$ on the right side. molecules $\left(a, a_{3}\right)$ and a copper atom $\left(\mathrm{Cu}_{\mathrm{B}}\right)$ and that subunit 2 contains a binding site for another copper atom $\left(\mathrm{Cu}_{\mathrm{A}}\right)$ and provides a site for interaction with cytochrome $c(10,39-41)$. Therefore, the decreased content of subunit 2 seems to be the main reason for the decreased activity of the complex.

In a patient with mitochondrial myopathy due to complex III deficiency (15) and in patients with MELAS due to complex I deficiency (42), it was demonstrated that deficiency of subunits in respective complexes was disproportionate; some subunits were severely deficient and others were less severely deficient. In the muscle tissue of the present patient, despite the increased amount of immunoreactive material in the ragged-red fibers, the histochemical stain for activity of complex IV (Fig. 1) was decreased, suggesting that the enzyme protein is inactive in those fibers. Inasmuch as we used an antiserum containing antibodies against various subunits of complex IV, the increased immunoreactivity is ascribable to the residual immunoreactive subunits that are retained in the markedly increased numbers of mitochondria in the ragged-red fibers. Similar observation was made in muscle tissues from patients with mitochondrial myopathies due to deficiency of complexes I and/or IV (43). Therefore, ragged-red fibers with decreased enzymic activity but with increased immunoreactive material seem to be an indication of impaired molecular assembly of the complex.

Combined deficiencies of multiple respiratory-chain enzyme complexes have been reported in several cases of fatal infantile mitochondrial myopathies (10-13). We previously observed that mild deficiency of complex IV subunits was associated with deficiency of complex I in a patient with MELAS (44). Moreover, we also observed combined deficiencies of complexes I and IV in two patients with mitochondrial myopathies (45). In the present study, it is demonstrated that milder but significant defects in complexes I and III (Fig. 5) and deficiency of several unidentified polypeptides (Fig. 6) accompanied deficiency of complex IV subunits (Figs. 3 and 4). These observations suggest that deficiency of multiple sites in the respiratory chain is not a rare phenomenon in mitochondrial myopathies.

Although it cannot be ruled out that the minor defects in complexes I and III are only epiphenomena of complex IV deficiency, these minor defects might be etiologically linked to the major defect in complex IV. Mammalian mitochondrial DNA codes for two ribosomal RNA, 22 transfer RNA, seven subunits in complex I, cytochrome $b$ subunit in complex III, subunits 1,2 , and 3 in complex IV, and subunits 6 and 8 in complex $\mathrm{V}(46,47)$. The genes encoding these proteins are transcribed in the forms of polycistronic RNA, which are processed into messenger RNA and translated on mitochondrial ribosomes (48). The pleiotropy of the defects in the electrontransfer chain found in the present patient might be caused by a defect in mitochondrial DNA itself or its expression. Specifically, the defect of subunit 2 in the present patient might be ascribed to a mutation or deletion in the COII gene in the mitochondrial DNA as in the cases reported by Ozawa et al. (49). The observation that complex IV deficiency was localized in the skeletal muscle in the present patient might be explained by mitotic segregation of a mutant mitochondrial genome in the muscle tissue early in the development of the patient. The elucidation of the underlying genetical abnormality awaits further molecular biologic approaches.

\section{REFERENCES}

1. Carafoli E, Roman I 1985 Mitochondria and disease. Mol Aspects Med 3:295429

2. DiMauro S, Bonilla E, Zeviani M, Nakagawa M, DeVivo DC 1985 Mitochondrial myopathies. Ann Neurol 17:521-538

3. Boustany RN, Aprille JR, Halperin J, Levy H, DeLong GR 1983 Mitochondrial cytochrome deficiency presenting as a myopathy with hypotonia, external ophthalmoplegia, and lactic acidosis in an infant and as fatal hepatopathy in a second cousin. Ann Neurol 14:462-470

4. Zeviani M, Nonaka I, Bonilla E, Okino E, Moggio M, Jones S, DiMauro S 
1985 Fatal infantile mitochondrial myopathy and renal dysfunction caused by cytochrome $c$ oxidase deficiency: immunological studies in a new patient. Ann Neurol 17:414-417

5. DiMauro S, Nicholson JF, Hays AP, Eastwood AB, Papadimitriou A, Koenigsberger R, DeVivo DC 1983 Benign infantile mitochondrial myopathy due to reversible cytochrome $c$ oxidase deficiency. Ann Neurol 14:226-234

6. Servidei S, Lazaro RP, Bonilla E, Barron KD, Zeviani M, DiMauro S 1987 Mitochondrial encephalomyopathy and partial cytochrome $c$ oxidase deficiency. Neurology 37:58-63

7. Willems JL, Monnens LAH, Trijbels JMF, Veerkamp JH, Meyer AEFH, van Dam K, van Haelst U 1977 Leigh's encephalomyelopathy in a patient with cytochrome $c$ oxidase deficiency in muscle tissue. Pediatrics 60:850-857

8. Bresolin N, Moggio M, Ber L, Gallanti A, Prelle A, Nobile-Orazio E, Adobbati L, Ferrante C, Pellegrini G, Scarlato G 1987 Progressive cytochrome oxidase deficiency in a case of Kearns-Sayre syndrome: morphological, immunological, and biochemical studies in muscle biopsies and autopsy tissues. Ann Neurol 21:564-572

9. Byrne E, Dennett X, Trounce I, Henderson R 1985 Partial cytochrome oxidase $\left(a a_{3}\right)$ deficiency in chronic progressive external ophthalmoplegia. Histochemical and biochemical studies. J Neurol Sci 71:257-271

10. Hatefi Y 1985 The mitochondrial electron transport and oxidative phosphorylation system. Annu Rev Biochem 54:1015-1069

11. Sengers RCA, Trijbels JMF, Bakkeren JAJM, Ruitenbeek W, Fischer JC Janssen AJM, Stadhouders AM, ter Laak HJ 1984 Deficiency of cytochrome $b$ and $a a_{3}$ in muscle from a floppy infant with cytochrome oxidase deficiency. Eur J Pediatr 141:178-180

12. Tanaka M, Nishikimi M, Suzuki H, Ozawa T, Okino E, Takahashi H 1986 Multiple cytochrome deficiency and deteriorated mitochondrial polypeptide composition in fatal infantile mitochondrial myopathy and renal dysfunction. Biochem Biophys Res Commun 137:911-916

13. Van Biervliet JPGM, Bruinvis L, Ketting D, De Bree PK, Van der Heiden C Wadman SK 1977 Hereditary mitochondrial myopathy with lactic acidemia, a DeToni-Fanconi-Debre syndrome, and a defective respiratory chain in voluntary striated muscles. Pediatr Res 11:1088-1093

14. DiMauro S, Mendell JR, Sahenk Z, Bachman D, Scarpa A, Scofield RM Reiner C 1980 Fatal infantile mitochondrial myopathy and renal dysfunction due to cytochrome-c-oxidase deficiency. Neurology 30:795-804

15. Kennaway NG, Buist NRM Darley-Usmar VM, Papadimitriou A, DiMauro S, Kelley RI, Capaldi RA, Blank NK, D'Agostino A 1984 Lactic acidosis and mitochondrial myopathy associated with deficiency of several components of complex III of the respiratory chain. Padiatr Res 18:991-999

16. Sanadi DR, Pharo RL, Sordahl LA 1967 NADH-CoQ reductase-assay and purification. Methods Enzymol 10:297-302

17. Pennington RJ 1961 Biochemistry of dystrophic muscle. Mitochondrial succinate-tetrazolium reductase and adenosine triphosphatase. Biochem J 80:649-654

18. Wharton DC, Tzagoloff A 1967 Cytochrome oxidase from beef mitochondria. Methods Enzymol 10:245-250

19. Kagawa Y 1974 Dissociation and reassembly of the inner mitochondrial membrane. In: Korn ED (ed) Methods in Membrane Biology, vol 1. Plenum Press, New York, pp 201-269

20. Bookelman H, Trijbels JMF, Sengers RCA, Janssen AJM 1978 Measurement of cytochromes in human skeletal muscle mitochondria isolated from fresh and frozen stored muscle specimens. Biochem Med 19:366-373

21. Lowry OH, Rosebrough NJ, Farr AL, Randall RJ 1951 Protein measurement with the Folin phenol reagent. J Biol Chem 193:265-275

22. Crane FL, Glenn JL, Green DE 1956 Studies on the electron transfer system IV. The electron transfer particle. Biochim Biophys Acta 22:475-487

23. Hatefi Y 1978 Preparation and properties of NADH:ubiquinone oxidoreductase (complex I), EC 1.6.5.3 Methods Enzymol 53:11-14

24. Galante YM, Hatefi Y 1978 Resolution of complex I and isolation of NADH dehydrogenase and an iron-sulfur protein. Methods Enzymol 53:15-21

25. Rieske JS, Zaugg WS, Hansen RE 1965 Studies on the electron transfer system LIX. Distribution of iron and of the component giving an electron paramagnetic resonance signal at $\mathrm{g}=1.90$ in subfractions of complex III. $\mathrm{J}$ Biol Chem 239:3023-3030

26. Ozawa T, Tanaka M, Shimomura Y 1983 Crystallization of cytochrome $b c_{1}$ complex. Proc Natl Acad Sci USA 80:921-925
27. Fowler LR, Richardson SH, Hatefi Y 1962 A rapid method for the preparation of highly purified cytochrome oxidase. Biochim Biophys Acta 64:170-173

28. Tzagoloff A, MacLennan DH 1965 Studies of the electron-transfer system LXIV. Role of phospholipid in cytochrome oxidase. Biochim Biophys Acta 99:476-485

29. Capaldi RA, Hayashi H 1972 The polypeptide composition of cytochrome oxidase from beef heart mitochondria. FEBS Lett 26:261-263

30. Tanaka M, Ozawa T 1982 Molecular profile of highly purified beef heart cytochrome oxidase. Biochem Int 5:67-75

31. Vogel G 1979 An improved method for the isolation of mitochondrial ATPase $\left(F_{1}\right)$ from beef heart. Methods Enzymol 55:317-319

32. Sato $T$, Anno $M$, Arahata $K$, Nakamura $S$, Mukoyama $M$, Nakamura $H$, Ozawa T 1986 Immunocytochemical demonstration of cytochrome $c$ oxidase and Complex III in tissues from patients with mitochondrial encephalomyopathy. Muscle Nerve 9(suppl 5S):183

33. Kadenbach B, Jarausch J, Hartmann R, Merle P 1983 Separation of mam malian cytochrome $c$ oxidase into 13 polypeptides by a sodium dodecyl sulfate-gel electrophoretic procedure. Anal Biochem 129:517-521

34. Douglas M, Finkelstein D, Butow RA 1979 Analysis of products of mitochondrial protein synthesis in yeast: Genetic and biochemical aspects. Methods Enzymol 56:58-66

35. Merril CR, Goldman D, Van Keuren ML 1983 Silver staining methods for polyacrylamide gel electrophoresis. Methods Enzymol 96:230-239

36. Towbin H, Staehelin $T$, Gordon J 1979 Electrophoretic transfer of proteins from polyacrylamide gels to nitrocellulose sheets: procedure and some applications. Proc Natl Acad Sci USA 76:4350-4354

37. Saraste M, Penttilä T, Wikström M 1981 Quaternary structure of bovine cytochrome oxidase. Eur J Biochem 115:261-268

38. Sinjorgo KMC, Hakvoort TMB, Durak I, Draijer JM, Post JKP, Muijsers AO 1987 Human cytochrome $c$ oxidase isozymes from heart and skeletal muscle: purification and properties. Biochim Biophys Acta 850:144-150

39. Capaldi RA 1982 Arrangement of proteins in the mitochondrial inner membrane. Biochim Biophys Acta 694:291-306

40. Winter DB, Bruyninckx FG, Foulke NP, Grinich NP, Mason HS 1980 Location of heme a on subunits I and II and copper on subunit II of cytochrome $c$ oxidase. J Biol Chem 255:11408-11414

41. Ludwig B $1980 \mathrm{Heme} a a_{3}$-type cytochrome $c$ oxidase from bacteria. Biochim Biophys Acta 594:177-189

42. Ichiki T, Tanaka M, Nishikimi M, Suzuki H, Ozawa T, Kobayashi M, Wada Y 1988 Deficiency of subunits of Complex I and mitochondrial encephalomyopathy. Ann Neurol 23:287-294

43. Tanaka M, Nishikimi M, Suzuki H, Tada M, Ozawa T, Koga $Y$, Nonaka I 1987 Deficiency of subunits of complex I or IV in mitochondrial myopathies: immunochemical and immunohistochemical study. J Inherited Metab Dis 10:284-288

44. Tanaka $M$, Nishikimi $M$, Suzuki $H$, Ozawa $T$, Nishizawa $M$, Tanaka $K$ Miyatake T 1986 Deficiency of subunits in heart mitochondrial NADHubiquinone oxidoreductase of a patient with mitochondrial encephalomyopathy and cardiomyopathy. Biochem Biophys Res Commun 140:88-93

45. Tanaka M, Nishikimi M Suzuki H, Ozawa T, Koga Y, Nonaka I 1987 Partial deficiency of subunits in complex I or IV of patients with mitochondrial myopathies. Biochem Int 14:525-530

46. Anderson S, Bankier AT, Barrell BG, de Bruijn MHL, Coulson AR, Drouin J, Eperon IC, Nierlich DP, Roe BA, Sanger F, Schreier PH, Smith AJH, Staden R, Yang IG 1981 Sequence and organization of the human mitochondrial genome. Nature 290:457-465

47. Chomyn A, Mariottini P, Cleeter MWJ, Ragan CI, Doolittle RF, MatsunoYagi A, Hatefi Y, Attardi G 1985 Function assignment of the products of the unidentified reading frames of human mitochondrial DNA. In: Quagliariello E, Slater EC, Palmieri F, Saccone C, Kroon AM (eds) Achievements and Perspectives of Mitochondrial Research, Vol II: Biogenesis. Elsevier Science Publishers, Amsterdam, pp 259-275

48. Clayton DA 1984 Transcription of the mammalian mitochondrial genome. Annu Rev Biochem 53:573-594

49. Ozawa T, Yoneda M, Tanaka M, Ohno K, Sato W, Suzuki H, Nishikimi M, Yamamoto M, Nonaka I, Horai S 1988 Maternal inheritance of deleted mitochondrial DNA in a family with mitochondrial myopathy. Biochem Biophys Res Commun (in press) 